\title{
Determining if $T$ cell antigens are naturally processed and presented on HLA class I molecules
}

\author{
Jay Friedman ${ }^{1}$, Sreenivasulu Gunti ${ }^{1}$, Maxwell Lee ${ }^{1}$, Ke Bai ${ }^{1}$, Christian Hinrichs ${ }^{2}$ and Clint T. Allen ${ }^{1 *}$
}

\begin{abstract}
Background: Determining T cell responses to naturally processed and presented antigens is a critical immune correlate to determine efficacy of an investigational immunotherapeutic in clinical trials. In most cases, minimal epitopes and $\mathrm{HLA}$ restriction elements are unknown.

Results: Here, we detail the experimental use of ex vivo expanded autologous B cells as antigen presenting cells to overcome the limitation of unknown HLA restriction, and the use of electroporated full length mRNA encoding full length parental proteins to ensure that any observed $T$ cell responses are specific for antigens that are naturally processed and presented.

Conclusions: This technique can serve as useful experimental approach to determine the induction or enhancement of specific responses to naturally processed and presented antigens on HLA class I molecules in peripheral blood or tumor infiltrating $T$ cells.
\end{abstract}

Keywords: HLA restriction, Antigen presenting cells, Minimal epitope, Electroporation, T cell responses

\section{Background}

Most current Food and Drug Administration-approved and investigational immunotherapies for cancer are designed to augment, activate or replace $\mathrm{T}$ cell immunity. Examples include immune checkpoint blockade to unblock the activity of existing $\mathrm{T}$ cell clones, therapeutic vaccines to activate new or expand existing $\mathrm{T}$ cell clones, and adoptive transfer of $\mathrm{T}$ cells to replace the existing T-lymphocyte repertoire [1-3]. The ability to experimentally detect antigen-specific responses in $\mathrm{T}$ cells from the periphery or tumor is a critical readout to demonstrate the efficacy of these treatments. However, especially when $\mathrm{T}$ cells being studied are isolated from patients

\footnotetext{
*Correspondence: clint.allen@nih.gov

1 Section on Translational Tumor Immunology, National Institute on Deafness and Other Communication Disorders, National Institutes of Health, Building 10, Room 7N240C, Bethesda, MD 20892, USA Full list of author information is available at the end of the article
}

with non-virally driven malignancies, the minimal antigenic epitope is often unknown.

The use of antigen presenting cells (APCs) loaded with overlapping peptides spanning the candidate protein from which the minimal epitope may be derived is a common approach to assess such $\mathrm{T}$ cell responses. The exogenous application of peptides 15 amino acids in length (15mer) overlapping by 11 amino acids can induce CD4+ and CD8+ T lymphocyte responses [4, 5]. This indicates that APCs can cross present human leukocyte antigen (HLA) class I-restricted antigens after endocytosis of exogenous peptides. Surface loading of antigenic peptide can also occur in select conditions [6,7]. Use of $15 \mathrm{mer}$ peptides also allows the determination of putative minimal epitopes responsible for observed $\mathrm{T}$ cell responses. However, this approach may bypass one or more steps in the natural processing and presentation of antigen derived from an endogenous intracellular full-length protein, potentially leading to falsely positive results [8]. 
As tumor-associated antigens or tumor-specific antigens presented via HLA class I molecules are derived from endogenous intracellular proteins within cancer cells, $\mathrm{T}$ cells responses are clinically relevant only if they are specific for antigen that is naturally processed and presented from the parental protein. Efficient techniques to screen if an observed antigen-specific $\mathrm{T}$ cells response is against an antigen that is naturally processed and presented form the parental protein are needed.

Introduction of nucleic acid encoding a whole protein into APCs to mimic an endogenous intracellular protein is one approach to ensure experimentally observed $\mathrm{T}$ cell responses are specific for a naturally processed and presented antigen. Here we describe a validated method of electroporating full-length mRNA into autologous APCs for use in T cell co-cultures and assessment of antigen-specific $\mathrm{T}$ lymphocyte responses.
Autologous B cells, which can be readily expanded in culture for experimental use, were used as APCs. T cells engineered to express a previously characterized $\mathrm{T}$ cell receptor (TCR) targeting HPV $16 \mathrm{E}_{11-19}$ presented via HLA-A*02 were utilized as effector $T$ cells in validation experiments. A schematic overview of the process is detailed in Fig. 1. This approach does not assist in the identification of minimal epitopes or HLA restriction elements for a given $\mathrm{T}$ cell response but does ensure that an observed $\mathrm{T}$ cell responses is specific for an epitope that is naturally processed and presented from a candidate endogenous full-length parental protein. Such approaches may be useful when tracking the development of antigen-specific $\mathrm{T}$ cell responses following immunotherapy or in the process of discovering potentially therapeutic TCRs.

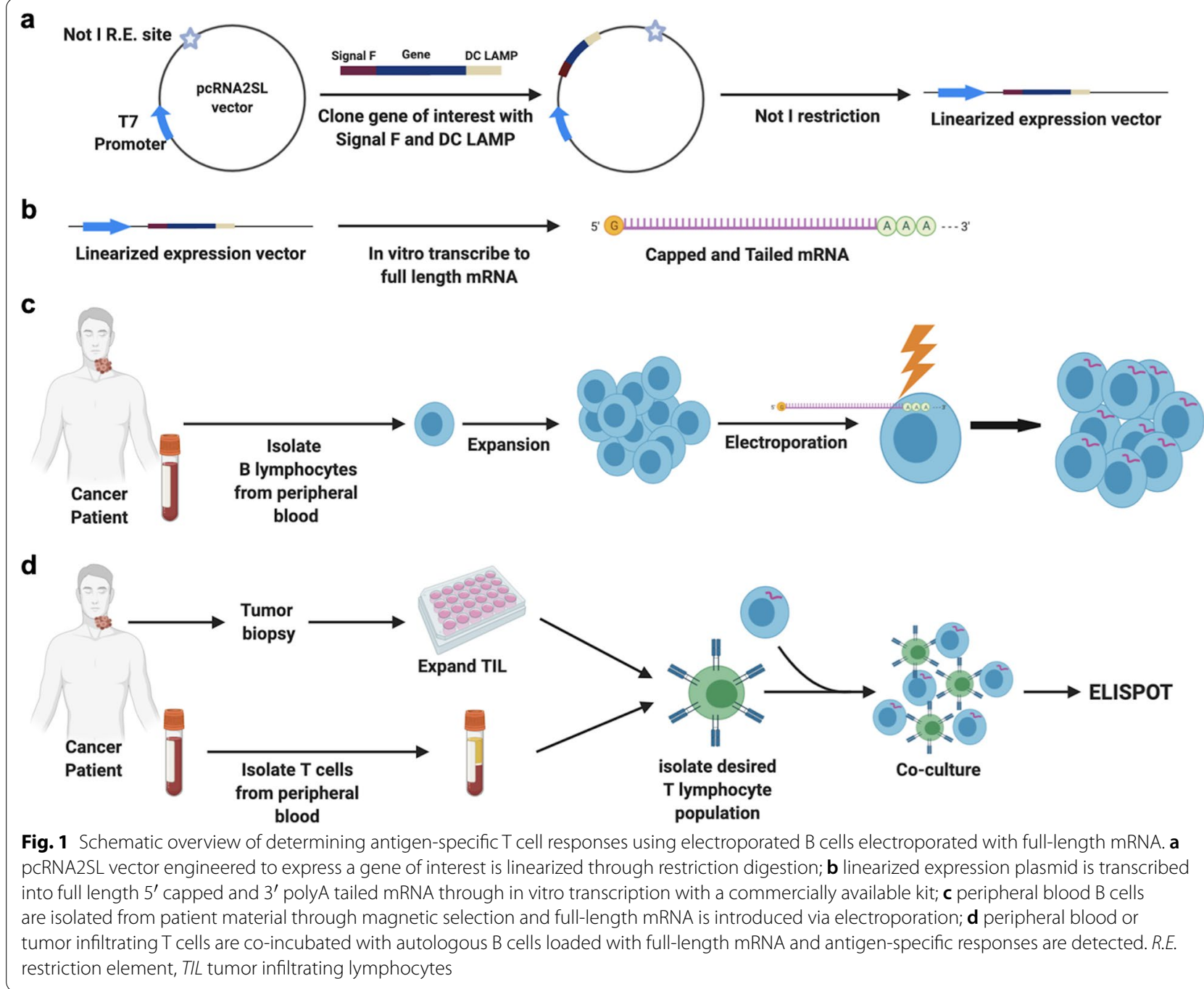




\section{Results}

\section{B cells used for APCs efficiently expanded in culture}

In this experimental system, B cells to be used as APCs were isolated via positive magnetic selection from deidentified, cryopreserved HLA-A*02 positive healthy donor peripheral blood mononuclear cells (PBMC) from the NIH Clinical Center Blood Bank. PBMC from the same donor were retrovirally transduced with an HPV16 E7 11-19-specific, HLA-A*02:01-restricted TCR to create an autologous system. Isolated $B$ cells readily expand in culture $\sim 50$-fold over a seven-day period (Fig. 2a). These data suggested that $B$ cells can be readily expanded as needed for desired experimental conditions.

\section{B cells were readily electroporated with mRNA and remain viable}

Expanded autologous B cells were electroporated with mRNA encoding full length HPV 16 E7. As a positive control for electroporation efficiency, separate $\mathrm{B}$ cells were electroporated with mRNA encoding GFP and analyzed $24 \mathrm{~h}$ later by fluorescent imaging and flow cytometry for green fluorescent protein (GFP) fluorescence. Fluorescent imaging revealed GFP fluorescence in cells electroporated with GFP (Fig. 2b). Flow cytometric analyses demonstrated that $>90 \%$ of B cells express GFP following electroporation (Fig. 2c), indicating that electroporation of GFP mRNA can be used as a positive control indicating successful electroporation. High B cell viability was observed following electroporation without mRNA (control) or following electroporation with GFP mRNA or HPV16 E7 mRNA (Fig. 2d). Further, B cells expanded in culture expressed activation markers CD80, CD86 and HLA-DR to a greater degree than B cells that were not expanded. Expression of these activation markers did not significantly change following electroporation (Fig. 2e). These data suggest that ex vivo B cells can be electroporated with mRNA of interest and that electroporated B cells remain viable and express CD80/86 and HLA-DR required for TCR co-stimulation and cross presentation of intracellular antigen, respectively.

\section{Co-culture of antigen-loaded B cells with TCR engineered T cells allowed detection of antigen specific responses}

ELISpot was used to detect antigen specific $\mathrm{T}$ cell responses upon co-culture with autologous B cells. As a model of antigen-specific T cells, CD8+ cells isolated from healthy donor PBMC were transduced to stably express an HPV16 E7-sepcific, HLA-A*02 restricted TCR. Co-culture of these TCR engineered T cells with B cells pulsed with E7 $7_{11-19}$ minimal epitope, but not an irrelevant 9mer peptide from EBV LMP2, resulted in robust IFNy production and a high spot count (Fig. 3a, b). Co-culture of TCR engineered T cells with B cells pulsed with the same concentration of 15mer overlapping peptide spanning HPV 16 E7, but not overlapping peptide spanning HPV $11 \mathrm{E} 7$, resulted in IFNY production but to a lesser degree than that observed with the minimal epitope. Finally, co-culture of TCR engineered $T$ cells with $B$ cells electroporated with mRNA encoding full length HPV 16 E7, but not mRNA encoding full length HPV $11 \mathrm{E} 7$, resulted in robust IFN $\gamma$ production and a high spot count. These data suggested that autologous $\mathrm{B}$ cells were able to efficiently process and present a known $\mathrm{T}$ cell antigen following electroporation with full length mRNA encoding the parental protein.

\section{Discussion}

Processing and presentation of a $\mathrm{T}$ cell antigen from an endogenous intracellular full length protein is a complex multi-step process [9]. The key advantage of using APCs electroporated with mRNA encoding full protein as a candidate $\mathrm{T}$ cell antigen source is that any observed $\mathrm{T}$ cell responses are specific for an intracellular antigen that must be naturally processed and presented. This result indicates that the same antigen may be naturally processed and presented on cancer cells from the same patient. Loading APCs with exogenous peptides can lead to presentation of antigen on HLA class I and class II molecules, but such peptides may bypass one or more steps in antigen processing that is observed with antigen derived from an endogenous intracellular full-length protein $[4,10]$. Doubrovina et al. identified 36 putative HLA-class I-restricted $\mathrm{T}$ lymphocyte epitopes using APCs pulsed with 15 mer overlapping peptides spanning the parental protein. One quarter of these $\mathrm{T}$ lymphocyte responses were absent when APCs expressing the fulllength endogenous protein were used instead of APC pulsed with 15 mer peptides [8]. These data support that the repertoire of HLA class I-restricted T lymphocyte antigens derived from endogenously expressed intracellular protein is more restrictive than that derived from overlapping 15 mer peptides, and that the use of $15 \mathrm{mer}$ overlapping peptide could lead to the identification of $\mathrm{T}$ cell antigens that are not naturally processed and presented from an intracellular full-length protein and thus clinically irrelevant.

Another potential pitfall of using APC pulsed with exogenous 15 mer peptide solely to determine the presence of antigen-specific $\mathrm{T}$ cell responses is that the concentration of peptides that enter cells may be significantly greater than the concentration of peptides derived from natural processing and presentation of intracellular full-length protein. Competition for HLA pocket binding is well established [11, 12], and commonly used peptide concentrations in the micromolar range may skew the HLA class I peptidome toward 


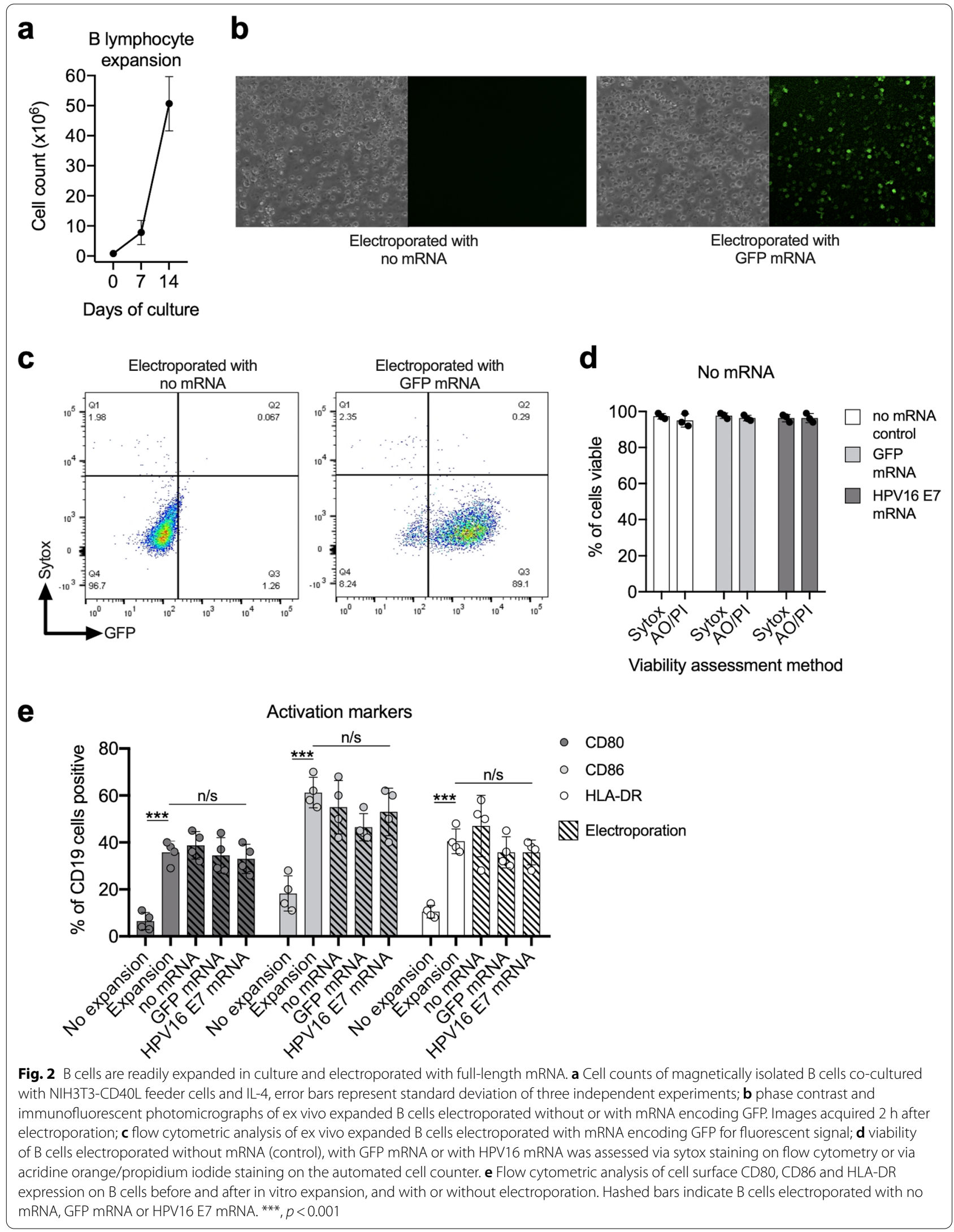



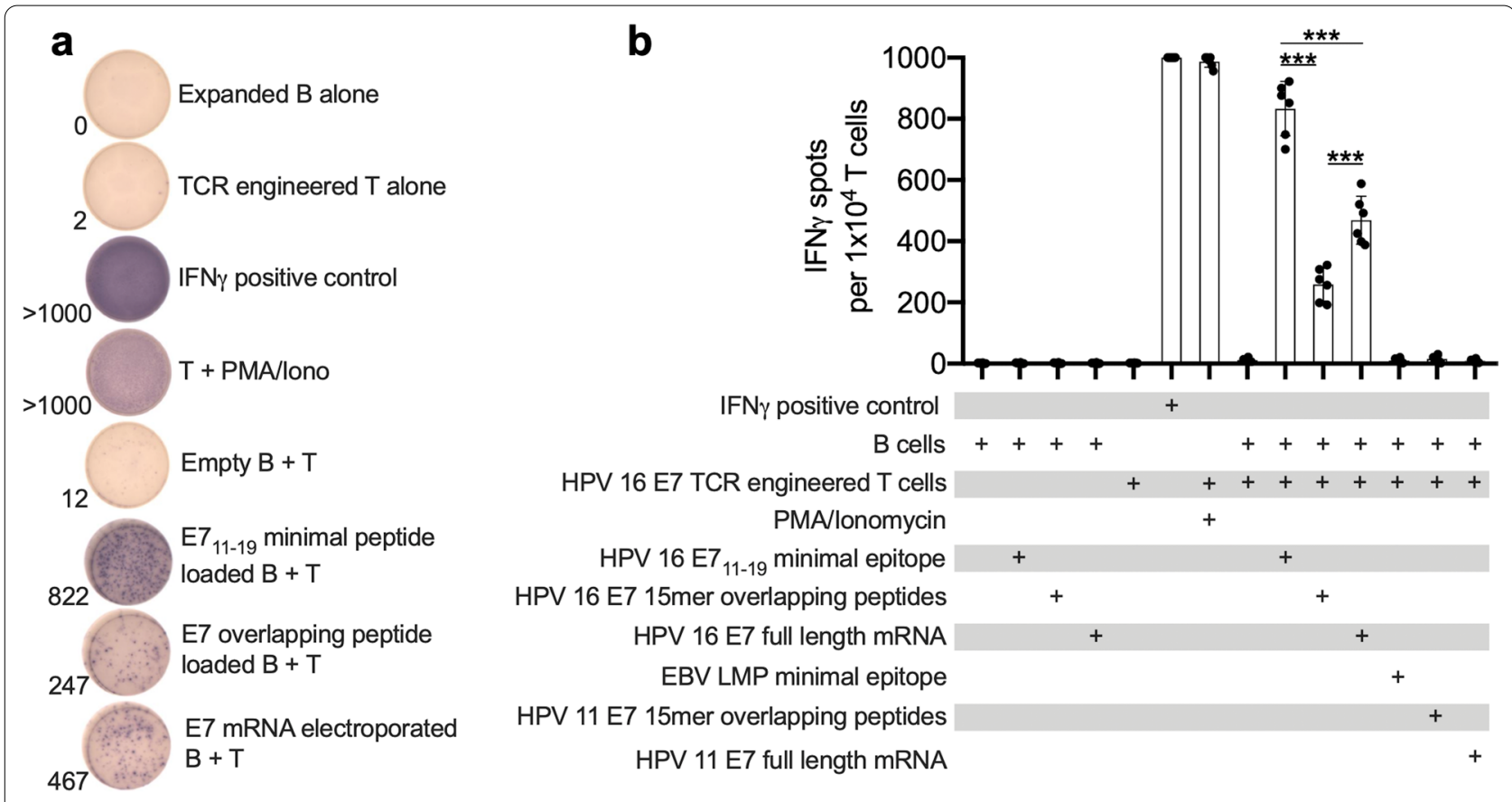

Fig. 3 B cells naturally process and present minimal epitope from electroporated full-length mRNA. a Representative photographs of ELISpot wells resulting from co-culture of expanded autologous $B$ cells loaded with E7 $7_{11-19}$ minimal peptide or 15 mer overlapping peptide spanning the entire E7 protein, electroporated with mRNA encoding full-length E7, or controls for each condition; $\mathbf{b}$ quantification of IFNy spots from all experimental controls and conditions. Spot counts greater than or equal to 1000 are depicted as 1000 . Representative results from one of three independent assays with similar results. ${ }^{* * *}, p<0.001$

pulsed peptide or displace low affinity but naturally processed and presented intracellular antigens. Electroporating mRNA encoding full length protein into cells may allow more physiologic levels of intracellular protein to be translated, processed, and loaded onto class I molecules for presentation to $\mathrm{T}$ cells. In our experiments, electroporation of mRNA encoding full length HPV 16 E7 led to greater activation of TCR engineered T cells upon co-culture compared to $\mathrm{B}$ cells pulsed with 15 mer overlapping peptide spanning HPV 16 E7 but reduced activation compared to E7 ${ }_{11-19}$ minimal epitope peptide. Greater activation of TCR engineered $\mathrm{T}$ cells with minimal epitope compared to $15 \mathrm{mer}$ overlapping peptide would be expected given that the 15 mer peptide pool was loaded into B cells at the same concentration $(0.1 \mu \mathrm{g} / \mathrm{mL})$ but consists of 22 total 15 mer peptides. However, these experimental conditions are not directly comparable as the quantity of antigenic material entering APCs under these different conditions in uncontrolled and 15mer peptides must be processed inside cells to a degree to be loaded onto HLA class I. These data simply confirm that CD40L-activated B cells can process and present a $\mathrm{T}$ cell antigen when pulsed with minimal epitope, 15mer overlapping peptide and when electroporated with mRNA.

The use of TCR engineered T cells as a model antigenspecific $\mathrm{T}$ cell may allow detection of greater magnitude responses compared to those observed from low-frequency, naturally occurring $\mathrm{T}$ cells. TCR engineered $\mathrm{T}$ cells were used in this work to demonstrate proof-ofprinciple responses against APCs loaded with peptide or electroporated with full length mRNA. Low frequency antigen-specific $\mathrm{T}$ cell clonotypes may need to be expanded with one or more rounds of in vitro stimulation before experimental detection can occur. The frequency of a $\mathrm{T}$ cell clonotype that required to detect responses upon co-culture with APC loaded with mRNA is unclear and required further determination.

Cells other than B cells can be used as APCs. Dendritic cells can be isolated or cultured and matured from PBMC but require high cell numbers to generate a reasonable number of cells for experimental use [13]. B cells are readily isolated by magnetic sorting, and readily expand upon exposure to CD40L and IL-4 to numbers that allow a large variety of experimental conditions [14-16]. Tumor cells may process and present antigen differently than professional APCs 
of hematopoietic origin. Use of B cells as APCs may not fully model how antigen-specific $\mathrm{T}$ cells would response to a tumor cell presenting cognate antigen, but rather simply serve as an experimental tool to determine the antigen-specificity of a given $\mathrm{T}$ cell clonotype.

When designing expression vectors for the mRNA encoding the full-length protein of interest, inclusion of trafficking or degradation signals proteins can shuttle protein toward HLA class I or II processing. This could allow detection of antigen-specific CD8 or CD4 $\mathrm{T}$ cells restricted to antigen presented on HLA class I or II, respectively. Whereas engineering HPV 16 E7 to express a ubiquitin tag would promote proteasomal degradation and initiation of antigen processing for the HLA class I pathway [17], we flanked our gene of interest (HPV 16 E7) with Signal F and DC-LAMP. Signal $\mathrm{F}$ is derived from the N-terminal of LAMP-1 and is a signal peptide used to target proteins to the endoplasmic reticulum, and DC-LAMP is a lysosome-associated membrane glycoprotein that contains a sorting signal that mediates lysosomal targeting and aids in the processing of antigen within phagosomes in the HLA class II pathway [18-20]. Though not experimentally determined here, these modifications may allow efficient processing and presentation of HLA class IIrestricted antigens. Our experimental validation that the HPV $16 \mathrm{E7}_{11-19}$ epitope is presented via HLA-A*02 while flanked with Signal F and DC-LAMP suggests that HLA class I-restricted epitopes are still naturally processed and presented from full length intracellular protein despite these lysosomal pathway-targeting signals. Both CD8+ and CD4+ T cells play important effector roles in anti-tumor immunity [21], and investigators interested in querying antigen-specific responses in pools containing both CD8+ and CD4+ $T$ cells should consider inclusion of Signal F and DCLAMP in mRNA expression constructs.

Potential limitations of using electroporated mRNA to mimic intracellular protein for the query of antigen-specific $\mathrm{T}$ cell responses are cost and technical considerations. Engineering expression vectors for each candidate protein of interest form which a $\mathrm{T}$ cell antigen may be derived can be costly. The experimental techniques involved in electroporation of autologous expanded APCs with in vitro transcribed mRNA are more complicated than pulsing APCs with $15 \mathrm{mer}$ overlapping peptides. A reasonable approach may be to use overlapping $15 \mathrm{mer}$ peptide to screen for positive antigen-specific $\mathrm{T}$ lymphocyte responses, with validation that responses are specific for naturally processed and presented antigen via electroporation of mRNA.

\section{Conclusions}

In conclusion, the ability to accurately assess peripheral or tumor infiltrating $\mathrm{T}$ cells for antigen-specific responses is an important correlative readout for clinical trials. In cases where the antigenic minimal epitope or HLA restriction element are not known, the use of autologous cells as APCs ensures HLA compatibility, but the technique used to introduce protein from which the antigenic minimal epitope may be derived may influence experimental outcomes. The approach of electroporating mRNA encoding full-length protein into APCs ensures that any positive responses upon co-culture with $\mathrm{T}$ cell pools of interest are to naturally processed and presented antigens. This approach should be considered by investigators when it is important to ensure that experimentally observed $\mathrm{T}$ cell responses are to naturally processed and presented antigens.

\section{Methods NIH3T3-CD40L cell line}

The NIH3T3-CD40L cell line, described previously [22], was cultured at $37^{\circ} \mathrm{C}$ with $5 \% \mathrm{CO}_{2}$ in DMEM media containing $10 \%$ heat inactivated human serum, $100 \mathrm{U} / \mathrm{mL}$ penicillin, $100 \mu \mathrm{g} / \mathrm{mL}$ streptomycin, $5 \mu \mathrm{g} / \mathrm{mL}$ gentamycin, $2 \mathrm{mM}$ L-glutamine and $25 \mathrm{mM}$ HEPES buffer.

\section{Purification and expansion of autologous $B$ cells}

$B$ cells were isolated form PBMC via positive magnetic selection using CD19 microbeads per manufacturer recommendations on an autoMACS Pro Separator (Miltenyi Biotec). B cells $\left(5 \times 10^{6}\right)$ were then co-cultured in a T-175 flask at $37{ }^{\circ} \mathrm{C}$ with $5 \% \mathrm{CO}_{2}$ with irradiated $(6000 \mathrm{rad})$ NIH3T3-CD40L feeder cells $[14,15]$ at a $1: 1$ ratio in $20 \mathrm{~mL}$ of complete B cell media consisting of IMDM, $10 \%$ heat inactivated human serum, $100 \mathrm{U} / \mathrm{mL}$ penicillin, $100 \mu \mathrm{g} / \mathrm{mL}$ streptomycin, $5 \mu \mathrm{g} / \mathrm{mL}$ gentamycin, $2 \mathrm{mM}$ L-glutamine and $200 \mathrm{U} / \mathrm{mL}$ IL-4 [16]. Media was freshened on day 3 by adding an additional $10 \mathrm{~mL}$ of media. Expanded B cells were harvested and counted on day 7 . If necessary, co-culture with NIH3T3-CD40L cells was repeated until B cells were expanded to numbers needed for experimental use. Cells were counted on a Nexcelom Cellometer Auto 2000 using acridine orange/propidium iodide per manufacturer recommendations.

\section{Generation of in vitro transcribed (IVT) mRNA}

pcRNA2SL expression plasmids encoding GFP, HPV 16 E7 or HPV 11 E7, flanked by Signal F and DC-LAMP, were generated commercially (GenScript). Plasmid linearization was accomplished in a $6 \mu \mathrm{L}$ reaction volume by combining $1 \mu \mathrm{g}$ of plasmid $(0.5 \mu \mathrm{g} / \mu \mathrm{L})$ with SmartCut buffer and NotI HF restriction enzyme (New England 
Biolabs) per manufacturer recommendations. Following incubation at $37{ }^{\circ} \mathrm{C}$ overnight in an Applied Biosystems thermal cycler, the reaction mixture was heat inactivated for $20 \mathrm{~min}$ at $65{ }^{\circ} \mathrm{C}$, followed by a 5 -min incubation at $4{ }^{\circ} \mathrm{C}$. mRNA was transcribed and polyadenylated from $1 \mu \mathrm{g}$ of linearized expression construct using the mMESSAGE mMACHINE T7 ULTRA Transcription Kit per manufacturer instructions (Thermo Fisher Scientific). IVT mRNA was purified using the RNeasy Mini Kit (Qiagen).

\section{Electroporation of APCs}

Eight $\mu \mathrm{g}$ of IVT GFP, HPV 16 E7 or HPV 11 E7 (control) mRNA was added to an electroporation cuvette containing $5 \times 10^{6}$ expanded B cells (100 $\mu \mathrm{L}$ volume) in OptiMEM and mixed gently by hand. Electroporation was performed using a BTX electroporator (BTX Harvard Apparatus; 150 V, 20 ms, 1 pulse). Electroporated B cells were immediately transferred to polypropylene tubes containing complete B cell media and housed at $37{ }^{\circ} \mathrm{C}$ with $5 \% \mathrm{CO}_{2}$ until used experimentally.

\section{Peptide pulsing of APCs}

Expanded B cells $\left(4 \times 10^{5}\right.$ cells $)$ were suspended in $1 \mathrm{~mL}$ complete B cell media and incubated with $0.1 \mu \mathrm{g} / \mathrm{mL}$ of either pooled $15 \mathrm{mer}$ (overlapping by 11 amino acids) peptides spanning HPV 16 E7 or $0.1 \mu \mathrm{g} / \mathrm{mL}$ of E7 ${ }_{11-19}$ peptide at $37^{\circ} \mathrm{C}$ with $5 \% \mathrm{CO}_{2}$ for $1 \mathrm{~h}$. B cells were washed in complete $\mathrm{B}$ lymphocyte media prior to co-culture with TCR engineered $T$ cells. In some conditions, pooled 15mer overlapping peptides spanning HPV 11 E7 or a 9mer peptide derived from the Epstein-Barr Virus latent membrane protein 2 (EBV LMP) were used as controls.

\section{TCR engineered T cells}

$\mathrm{T}$ cells engineered to express a previously characterized

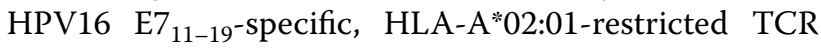
were generated as described [3]. Briefly, CD8 $+\mathrm{T}$ cells isolated from HLA-A*02 positive healthy donor PBMC via negative magnetic selection (Miltenyi Biotec) were retrovirally transduced with the HPV16 E7 $7_{11-19}$-specific, HLA-A*02:01-restricted TCR and cryopreserved. A mouse constant region was incorporated into the retroviral expression vector, and flow cytometry was used to verify that $>90 \%$ of transduced T cells expressed the TCR of interest. Cryopreserved TCR engineered T cells were thawed and rested overnight in media consisting of $50 \%$ AIM V media, 50\% RPMI media, 25 mM HEPES buffer, $5 \%$ heat inactivated human serum, $100 \mathrm{U} / \mathrm{mL}$ penicillin, $100 \mu \mathrm{g} / \mathrm{mL}$ streptomycin, $10 \mu \mathrm{g} / \mathrm{mL}$ gentamycin, $2 \mathrm{mM}$ L-glutamine, $1.25 \mu \mathrm{g} / \mathrm{mL}$ Amphotericin B and $6000 \mathrm{U} /$ $\mathrm{mL}$ IL-2 overnight prior to use.

\section{ELISpot}

Electroporated, $15 \mathrm{mer}$ overlapping peptide, or minimal epitope peptide-pulsed B cells $\left(2 \times 10^{4}\right)$ were cocultured with TCR engineered T cells $\left(1 \times 10^{4}\right)$ at a 2:1 ratio for $20 \mathrm{~h}$ at $37{ }^{\circ} \mathrm{C}$ with $5 \% \mathrm{CO}_{2}$, and ELISpot was performed per manufacturer recommendations. The final volume of each well was $200 \mu \mathrm{L} ; 100 \mu \mathrm{L}$ B cell media and $100 \mu \mathrm{L}$ T cell media. Spot counts for ELISpot assays were measured on an Immunospot ELISpot plate reader (Cellular Technology).

\section{Flow cytometry and fluorescence microscopy}

Freshly sorted or cultured B cells with or without electroporation were assessed for cell surface expression of surface protein markers using anti-human CD80 (clone 2D10), CD86 (IT2.2) and HLA-DR (L243) antibodies from Biolegend directly conjugated to fluorophores. Cells were suspended in 1X PBS containing 1\% BSA. Non-viable cells were excluded with sytox blue. Data was acquired with FACSDiva software on a BD Fortessa LSRII analyzer. Data was analyzed using FlowJo (VX10.0.7r2). Photomicrographs of B cells electroporated with IVT mRNA encoding GFP were obtained on an EVOS imaging system (Thermo).

\section{Statistics}

Comparison of multiple sets of data was achieved with one-way analysis of variance (ANOVA). Analysis was performed using GraphPad Prism v8.4.1.

\section{Abbreviations}

APC: Antigen processing cells; GFP: Green fluorescent protein; HLA: Human leukocyte antigen; PBMC: Peripheral blood mononuclear cells; TCR: T cell receptor.

\section{Acknowledgements}

The authors thank Dr. Claudia Palena and Dr. Nyall London for their critical review of this manuscript.

\section{Authors' contributions}

Substantial contributions to the conception or design of the work or the acquisition, analysis or interpretation of the data: JF, SG, ML, KB, CH, CTA. Drafting the work or revising it critically for important intellectual content: JF SG, ML, CTA. Final approval of the completed version: JF, SG, ML, KB, CH, CTA. Accountability for all aspects of the work: JF, SG, ML, KB, CH, CTA. All authors read and approved the final manuscript.

\section{Funding}

Open Access funding provided by the National Institutes of Health (NIH). This work was supported by the Intramural Research Program of the NIH, National Institute on Deafness and Other Communication Disorders, project number ZIA-DC000087.

\section{Availability of data and materials}

All data supporting the results of this work are included in the manuscript. All materials are available upon reasonable request to the corresponding author. 


\section{Declarations}

Ethics approval and consent to participate Not applicable.

\section{Consent for publication}

Not applicable.

\section{Competing interests}

The authors declare that no competing interests exist.

\section{Author details}

${ }^{1}$ Section on Translational Tumor Immunology, National Institute on Deafness and Other Communication Disorders, National Institutes of Health, Building 10, Room 7N240C, Bethesda, MD 20892, USA. ${ }^{2}$ Rutgers Cancer Center at Rutgers, The State University of New Jersey, New Brunswick, NJ, USA.

Received: 25 May 2021 Accepted: 28 January 2022

Published online: 11 February 2022

\section{References}

1. Burtness B, Harrington KJ, Greil R, Soulieres D, Tahara M, de Castro G, Jr, et al. Pembrolizumab alone or with chemotherapy versus cetuximab with chemotherapy for recurrent or metastatic squamous cell carcinoma of the head and neck (KEYNOTE-048): a randomised, open-label, phase 3 study. Lancet. 2019:394(10212):1915-28.

2. Massarelli E, William W, Johnson F, Kies M, Ferrarotto R, Guo M, et al. Combining immune checkpoint blockade and tumor-specific vaccine for patients with incurable human papillomavirus 16-related cancer: a phase 2 clinical trial. JAMA Oncol. 2019:5(1):67-73.

3. Jin BY, Campbell TE, Draper LM, Stevanovic S, Weissbrich B, Yu Z, et al. Engineered T cells targeting E7 mediate regression of human papillomavirus cancers in a murine model. JCI Insight. 2018;3(8):e99488.

4. Maecker HT, Dunn HS, Suni MA, Khatamzas E, Pitcher CJ, Bunde T, et al. Use of overlapping peptide mixtures as antigens for cytokine flow cytometry. J Immunol Methods. 2001;255(1-2):27-40.

5. Zhang $\mathrm{H}$, Hong H, Li D, Ma S, Di Y, Stoten A, et al. Comparing pooled peptides with intact protein for accessing cross-presentation pathways for protective CD8+ and CD4+ T cells. J Biol Chem. 2009:284(14):9184-91.

6. Wan X, Zinselmeyer BH, Zakharov PN, Vomund AN, Taniguchi R, Santambrogio $L$, et al. Pancreatic islets communicate with lymphoid tissues via exocytosis of insulin peptides. Nature. 2018;560(7716):107-11.

7. Ito Y, Ashenberg O, Pyrdol J, Luoma AM, Rozenblatt-Rosen O, Hofree $M$, et al. Rapid CLIP dissociation from MHC II promotes an unusual antigen presentation pathway in autoimmunity. J Exp Med. 2018;215(10):2617-35.

8. Doubrovina E, Carpenter T, Pankov D, Selvakumar A, Hasan A, O'Reilly RJ. Mapping of novel peptides of WT-1 and presenting HLA alleles that induce epitope-specific HLA-restricted T cells with cytotoxic activity against WT-1(+) leukemias. Blood. 2012;120(8):1633-46.

9. Blum JS, Wearsch PA, Cresswell P. Pathways of antigen processing. Annu Rev Immunol. 2013:31:443-73.

10. van Endert PM, Tampe R, Meyer TH, Tisch R, Bach JF, McDevitt HO. A sequential model for peptide binding and transport by the transporters associated with antigen processing. Immunity. 1994;1 (6):491-500.

11. Adorini L, Nagy ZA. Peptide competition for antigen presentation. Immunol Today. 1990;11(1):21-4.

12. Luft T, Rizkalla M, Tai TY, Chen Q, MacFarlan RI, Davis ID, et al. Exogenous peptides presented by transporter associated with antigen processing (TAP)-deficient and TAP-competent cells: intracellular loading and kinetics of presentation. J Immunol. 2001;167(5):2529-37.

13. Nair S, Archer GE, Tedder TF. Isolation and generation of human dendritic cells. Curr Protoc Immunol. 2012; Chapter 7:Unit7 32.

14. von Bergwelt-Baildon MS, Vonderheide RH, Maecker B, Hirano N, Anderson KS, Butler MO, et al. Human primary and memory cytotoxic T lymphocyte responses are efficiently induced by means of CD40-activated B cells as antigen-presenting cells: potential for clinical application. Blood. 2002:99(9):3319-25.
15. Lapointe R, Bellemare-Pelletier A, Housseau F, Thibodeau J, Hwu P. CD40stimulated $B$ lymphocytes pulsed with tumor antigens are effective antigen-presenting cells that can generate specific T cells. Cancer Res. 2003;63(11):2836-43.

16. Kondo E, Gryschok L, Klein-Gonzalez N, Rademacher S, Weihrauch MR, Liebig T, et al. CD40-activated B cells can be generated in high number and purity in cancer patients: analysis of immunogenicity and homing potential. Clin Exp Immunol. 2009;155(2):249-56.

17. Reinstein E, Scheffner M, Oren M, Ciechanover A, Schwartz A. Degradation of the E7 human papillomavirus oncoprotein by the ubiquitin-proteasome system: targeting via ubiquitination of the $\mathrm{N}$-terminal residue. Oncogene. 2000;19(51):5944-50.

18. Wu TC, Guarnieri FG, Staveley-O'Carroll KF, Viscidi RP, Levitsky HI, Hedrick $\mathrm{L}$, et al. Engineering an intracellular pathway for major histocompatibility complex class II presentation of antigens. Proc Natl Acad Sci U S A. 1995;92(25):11671-5.

19. Ji H, Wang TL, Chen CH, Pai SI, Hung CF, Lin KY, et al. Targeting human papillomavirus type 16 E7 to the endosomal/lysosomal compartment enhances the antitumor immunity of DNA vaccines against murine human papillomavirus type 16 E7-expressing tumors. Hum Gene Ther. 1999;10(17):2727-40

20. Wilke S, Krausze J, Bussow K. Crystal structure of the conserved domain of the DC lysosomal associated membrane protein: implications for the lysosomal glycocalyx. BMC Biol. 2012;10:62.

21. Tay RE, Richardson EK, Toh HC. Revisiting the role of CD4(+) T cells in cancer immunotherapy-new insights into old paradigms. Cancer Gene Ther. 2020;28:5-17.

22. Urashima M, Chauhan D, Uchiyama H, Freeman GJ, Anderson KC. CD40 ligand triggered interleukin-6 secretion in multiple myeloma. Blood. 1995;85(7):1903-12.

\section{Publisher's Note}

Springer Nature remains neutral with regard to jurisdictional claims in published maps and institutional affiliations.
Ready to submit your research? Choose BMC and benefit from:

- fast, convenient online submission

- thorough peer review by experienced researchers in your field

- rapid publication on acceptance

- support for research data, including large and complex data types

- gold Open Access which fosters wider collaboration and increased citations

- maximum visibility for your research: over $100 \mathrm{M}$ website views per year

At BMC, research is always in progress.

Learn more biomedcentral.com/submissions 